\title{
Effect of Inferior Vena Cava Filter on Venous Thromboembolism Mortality in Japan - JROAD and JROAD-DPC Registry Analysis -
}

\author{
Yoshiaki Ohyama, MD, PhD; Norimichi Koitabashi, MD, PhD; Tetsuya Nakamura, MD, PhD; \\ Yoko Sumita; Michikazu Nakai, PhD; Kunihiro Nishimura, MD, PhD; \\ Yoshihiro Miyamoto, MD, PhD; Masahiko Kurabayashi, MD, PhD
}

\begin{abstract}
Background: Previous randomized clinical studies have raised concerns about whether inferior vena cava filter (IVCF) can benefit patients with venous thromboembolism (VTE). The present study therefore investigated whether IVCF are associated with in-hospital mortality in Japan.

Methods and Results: This study was based on the Diagnosis Procedure Combination database in the Japanese Registry of All Cardiac and Vascular Datasets (JROAD-DPC). Of 2,368,165 patients included in JROAD-DPC, we identified 28,238 who were hospitalized with VTE between 2012 and 2014. We compared in-hospital mortality rates between patients with or without IVCF using propensity score (PS) matching. PS were estimated using logistic regression models in which IVCF was the dependent variable. The other variables consisted of age, sex, Charlson comorbidity index, anti-thrombotic agents and clinical disease status. Patients were aged $68 \pm 16$ years, and $59.7 \%$ were female. Of 28,238 patients, 6,937 (24.5\%) were treated with an IVCF. The overall in-hospital mortality was $4.3 \%$. On PS-matched analysis in-hospital mortality was significantly lower with, than without, IVCF (3.1\% vs. $4.4 \%$, $\mathrm{P}<0.001$; OR, 0.65; 95\% Cl: 0.54-0.79).
\end{abstract}

Conclusions: Having an IVCF was independently associated with lower in-hospital mortality in Japanese patients with VTE. This is in sharp contrast to the benefits of IVCF in other countries. The reasons for this difference require further investigation.

Key Words: Anticoagulation; Epidemiology; Inferior vena cava filter; Mortality; Pulmonary embolism

$\mathbf{V}$ enous thromboembolism (VTE), including deep vein thrombosis (DVT) and pulmonary embolism (PE), is a common medical condition and the third leading cause of cardiovascular death worldwide. ${ }^{1}$ The standard initial treatment for VTE is parenteral anticoagulation followed by vitamin $\mathrm{K}$ antagonists (VKA) and/or direct oral anticoagulants (DOAC). ${ }^{2}$ Thrombolysis is still required in extreme clinical situations. ${ }^{2}$ Anti-thrombotic agents should be used, considering the balance between the benefit and risk of each treatment strategy. ${ }^{3}$ Inferior vena cava filters (IVCF) trap venous emboli from the lower extremities and prevent clinically significant PE. ${ }^{4}$ More patients in Japan than in other countries have IVCF, including those who are being treated with standard anticoagulation. ${ }^{5}$ The Japan VTE Treatment Registry (JAVA) has found that $40 \%$ of patients with VTE have an IVCF. 5 Recent guidelines, however, do not recommend IVCF as primary treatment because randomized clinical trials have not found better mortality rates when IVCF is added to standard anticoagulation. ${ }^{3,6,7}$

Several retrospective analyses have shown a survival benefit of IVCF, especially in patients with confirmed risk of significant bleeding. ${ }^{8}$ In addition, others have found that IVCF confers a benefit upon patients with cancer-associated thrombosis, ${ }^{9}$ recurrent thrombosis despite anticoagulation, ${ }^{10}$ and VTE during pregnancy, ${ }^{11}$ suggesting that selected patients with VTE would benefit from an IVCF. Therefore, we extracted data on patients with VTE who were listed in the administrative case-mixed Japanese Registry of All Cardiac and Vascular Diseases-Diagnostic Procedure Combination (JROAD-DPC) maintained by the Japanese Circulation Society (JCS). ${ }^{12}$ We assessed associations between IVCF and in-hospital mortality after treatment for acute symptomatic VTE. This database covers almost all teach-

Received May 15, 2019; revised manuscript received June 5, 2019; accepted June 11, 2019; J-STAGE Advance Publication released online June 29, 2019 Time for primary review: 1 day

Clinical Investigation and Research Unit, Gunma University Hospital, Maebashi (Y.O., T.N.); Department of Cardiovascular Medicine, Gunma University Graduate School of Medicine, Maebashi (Y.O., N.K., M.K.); and Center for Cerebral and Cardiovascular Disease Information, National Cerebral and Cardiovascular Center, Suita (Y.S., M.N., K.N., Y.M.), Japan

Y.M. is a member of Circulation Reports' Editorial Team.

Mailing address: Norimichi Koitabashi, MD, PhD, Department of Cardiovascular Medicine, Gunma University Graduate School of Medicine, 3-39-22 Showa-machi, Maebashi 371-8511, Japan. E-mail: norikoitabashi@gmail.com

ISSN-2434-0790 All rights are reserved to the Japanese Circulation Society. For permissions, please e-mail: cr@j-circ.or.jp 


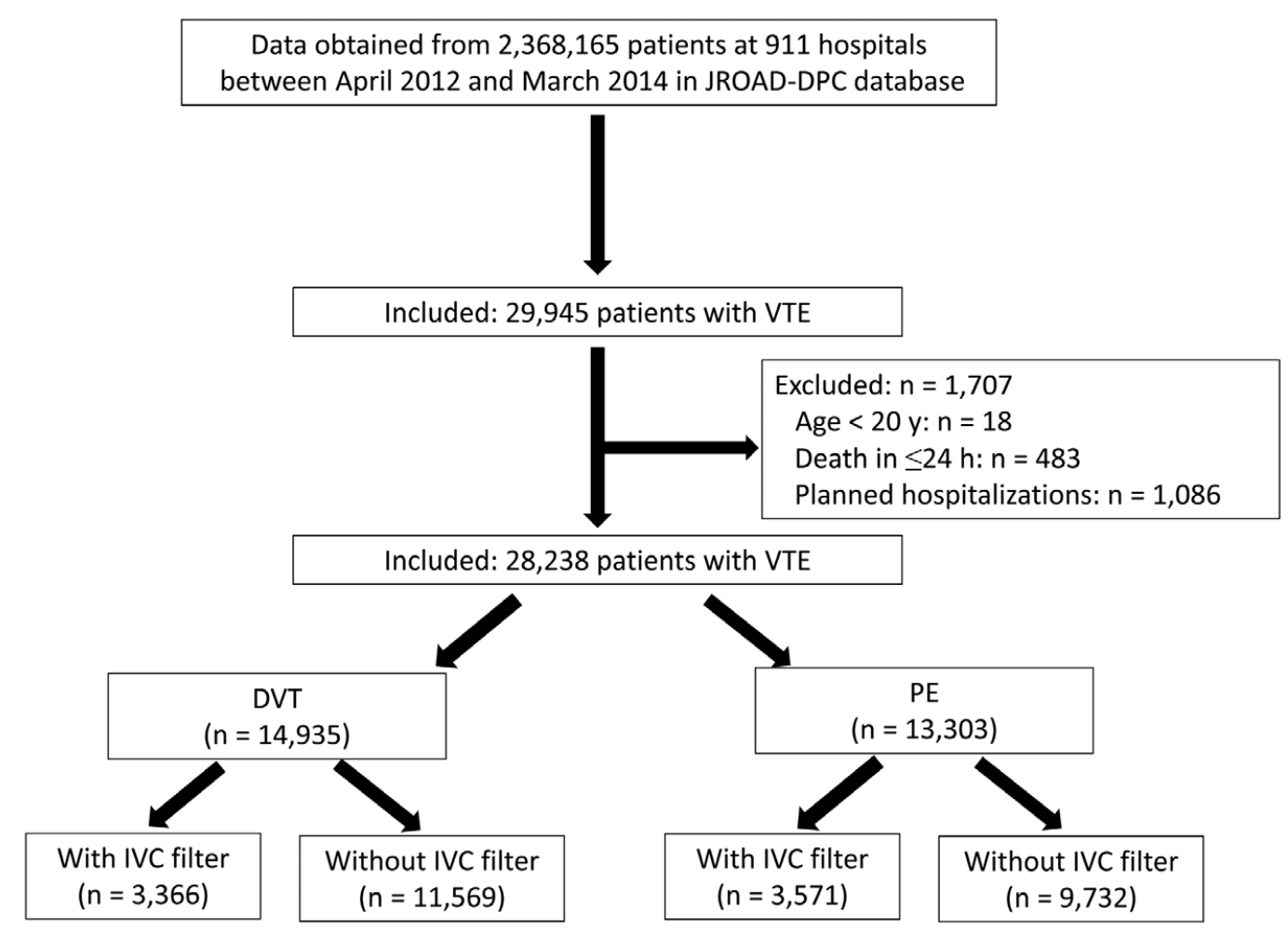

Figure 1. Patient selection. DVT, deep vein thrombosis; IVC, inferior vena cava; JROAD-DPC, Japanese Registry of All Cardiac and Vascular Diseases-Diagnostic Procedure Combination; PE, pulmonary embolism; VTE, venous thromboembolism.

ing hospitals with cardiovascular beds in Japan. Therefore, the present study of patients treated for VTE is the largest to date as far as we can determine.

\section{Methods}

This cross-sectional study extracted data from the JROADDPC database between 1 April 2012 and 31 March 2015. The ethics committees at both JCS and Gunma University approved the study protocol and waived the requirement for individual informed consent because information specific to individuals is not included. The original DPC data were rendered innominate using code change equations and were sent to the Ministry of Health, Labor, and Welfare.

\section{Subjects}

Of 2,368,165 patients at 911 hospitals in JROAD-DPC, we collected data on those hospitalized with VTE based on the International Classification of Diseases (ICD-10) codes for VTE as the main diagnosis at admission between 1 April 2012 and 31 March 2015. VTE includes PE (ICD-10 codes, I26.0, I26.9) and DVT (ICD 10 codes, I80.0, I80.1, I80.2, I80.3, I80.9, I82.2, I82.3, I82.9, O22.2, O22.3, O22.9, O87.0, O87.1, O87.9). We excluded 138 patients aged $<20$ years, 1,086 with planned hospitalizations, and 483 who died $\leq 24 \mathrm{~h}$ after admission. Consequently, we analyzed data from 28,238 patients with VTE (PE, n=13,303; DVT, $\mathrm{n}=14,935$ ) at 911 hospitals (Figure 1).

\section{Outcomes}

The main outcome measure was in-hospital mortality (total no. deaths during hospitalization). Death $\leq 7$ and 30 days after admission was assessed as secondary outcomes.

\section{Statistical Analysis}

Continuous variables are given as mean \pm SD and categorical variables as $\mathrm{n}(\%)$. We compared characteristics between patients with and without IVCF using Student's t-test. Categorical variables were analyzed using the chi-squared test. Because clinicians did not randomly allocate filter therapy, the baseline characteristics, clinical course and comorbidities are likely to have differed between patients with and without IVCF. Treatment effects were compared in patients with similar predicted probabilities of receiving a filter using propensity score (PS) adjustment. ${ }^{13}$ PS for patients with VTE, PE and DVT were estimated using logistic regression, and we modeled the log odds of the probability that a patient was treated with a filter using baseline demographic and clinical variables that were previously associated with mortality or treatment selection. These variables included age at admission, sex, Charlson comorbidity index, ${ }^{14}$ comatose at admission, mechanical ventilation and catecholamine medication at admission, mechanical support including intra-aortic balloon pumping (IABP) and percutaneous cardiopulmonary support (PCPS), blood transfusion, cancer, anticoagulant agents and thrombolytic therapy during hospitalization. In addition, PE was the main diagnosis in the model for VTE patients; DVT was a comorbidity at admission in the model for patients 


\begin{tabular}{|c|c|c|c|c|c|c|c|}
\hline \multirow[b]{2}{*}{ Characteristics } & \multirow{2}{*}{$\begin{array}{c}\text { All } \\
\text { participants } \\
(n=28,238)\end{array}$} & \multicolumn{2}{|c|}{ Unmatched patients } & \multirow[b]{2}{*}{ P-value } & \multicolumn{2}{|c|}{ PS-matched patients } & \multirow[b]{2}{*}{ P-value } \\
\hline & & $\begin{array}{c}\text { Without } \\
\text { IVCF } \\
(n=21,301)\end{array}$ & $\begin{array}{c}\text { With } \\
\text { IVCF } \\
(n=6,937)\end{array}$ & & $\begin{array}{l}\text { Without } \\
\text { IVCF } \\
(n=6,911)\end{array}$ & $\begin{array}{c}\text { With } \\
\text { IVCF } \\
(n=6,911)\end{array}$ & \\
\hline Age (years) & $68.2 \pm 16.1$ & $68.5 \pm 16.2$ & $67.4 \pm 15.6$ & $<0.001$ & $67.6 \pm 15.3$ & $67.4 \pm 15.6$ & 0.39 \\
\hline Female & $16,849(59.7)$ & $13,010(61.1)$ & $3,839(55.3)$ & $<0.001$ & $3,826(55.4)$ & $3,831(55.44)$ & 0.93 \\
\hline \multicolumn{8}{|l|}{ Comorbidities at admission } \\
\hline \multicolumn{8}{|l|}{$\mathrm{CCl}$} \\
\hline 0 & $11,550(40.9)$ & $8,774(41.2)$ & $2,776(40.0)$ & $<0.001$ & $2,784(40.3)$ & $2,774(40.1)$ & 0.99 \\
\hline 1 & $7,546(26.7)$ & $5,701(26.8)$ & $1,845(26.6)$ & & $1,789(25.9)$ & $1,840(26.6)$ & \\
\hline 2 & $5,236(18.5)$ & $3,917(18.4)$ & $1,319(19.0)$ & & $1,306(18.9)$ & $1,311(19.0)$ & \\
\hline$\geq 3$ & $3,906(13.9)$ & $2,909(13.6)$ & $997(14.4)$ & & $1,032(14.9)$ & $986(14.3)$ & \\
\hline PE & $13,303(47.1)$ & $9,732(45.7)$ & $3,571(51.5)$ & $<0.001$ & 3,545 (51.3) & $3,552(51.4)$ & 0.91 \\
\hline DVT & $14,935(52.9)$ & $11,569(54.3)$ & $3,366(48.5)$ & $<0.001$ & $3,366(48.7)$ & $3,359(48.6)$ & 0.91 \\
\hline \multicolumn{8}{|l|}{ Status on admission } \\
\hline Emergency & $23,933(84.8)$ & $17,770(83.5)$ & $6,163(88.9)$ & $<0.001$ & $6,135(88.8)$ & $6,138(88.8)$ & 0.94 \\
\hline Comatose & $265(0.9)$ & $217(1.0)$ & $48(0.7)$ & 0.014 & $34(0.5)$ & $48(0.7)$ & 0.12 \\
\hline On ventilator & $871(3.1)$ & $657(3.1)$ & $214(3.1)$ & 1 & $199(2.9)$ & $213(3.1)$ & 0.48 \\
\hline Catecholamines & $1,108(3.9)$ & $781(3.7)$ & $327(4.7)$ & $<0.001$ & $319(4.6)$ & $324(4.7)$ & 0.87 \\
\hline Mechanical support & $391(1.4)$ & $308(1.4)$ & $83(1.2)$ & 0.12 & $80(1.2)$ & $83(1.2)$ & 0.81 \\
\hline Blood transfusion in hospital & $876(3.0)$ & $568(2.7)$ & $275(4.0)$ & $<0.001$ & $238(3.4)$ & $265(3.8)$ & 0.22 \\
\hline Pregnancy & $525(1.9)$ & $425(2.0)$ & $100(1.4)$ & 0.004 & $99(1.4)$ & $100(1.4)$ & 0.71 \\
\hline Cancer & $5,318(18.8)$ & $3,827(18.0)$ & $1,491(21.5)$ & $<0.001$ & $1,533(22.2)$ & $1,473(21.3)$ & 0.22 \\
\hline \multicolumn{8}{|l|}{ Anti-thrombotic therapy } \\
\hline Anticoagulants & $25,666(91.2)$ & $18,821(88.7)$ & $6,845(98.7)$ & $<0.001$ & $6,817(98.6)$ & $6,819(98.7)$ & 0.88 \\
\hline Thrombolysis & $2,660(9.4)$ & $1,541(7.2)$ & $1,119(16.1)$ & $<0.001$ & $1,092(15.8)$ & $1,098(15.9)$ & 0.89 \\
\hline \multicolumn{8}{|l|}{ Outcome } \\
\hline Total in-hospital death & $1,204(4.3)$ & $987(4.6)$ & $218(3.1)$ & $<0.001$ & $307(4.4)$ & $211(3.1)$ & $<0.001$ \\
\hline 7 days & 897 (3.2) & $354(1.7)$ & $30(0.4)$ & $<0.001$ & $89(1.3)$ & $30(0.4)$ & $<0.001$ \\
\hline 30 days & $913(3.2)$ & $776(3.6)$ & $121(1.7)$ & $<0.001$ & $237(3.4)$ & $120(1.7)$ & $<0.001$ \\
\hline
\end{tabular}

Data given as mean \pm SD or $n(\%)$. CCI, Charlson comorbidity index; DVT, deep vein thrombosis; IVCF, inferior vena cava filter; PE, pulmonary embolism; PS, propensity score; VTE, venous thromboembolism.

with PE; and PE was a comorbidity at admission in the model for patients with DVT.

After generating PS, we estimated the reduction in hospital mortality attributable to the filter using a matchedpaired analysis with a 1:1 matching algorithm. We randomly selected patients with an IVCF and then matched them with the nearest patient without one, in a fixed caliper width of $0.25 \times \mathrm{SD}$. The data were analyzed according to the $3 \mathrm{PS}$ models: 1 each for VTE, PE, and DVT. We estimated the OR of having an IVCF for in-hospital mortality in each PS model using mixed-effects logistic regression models with each institute as a random effect. This analytic approach allowed variations in each institution to be considered in the association between IVCF and hospital mortality.

We examined associations between IVCF and death in the first 7 or 30 days after admission. We also analyzed subgroups stratified by age, sex, anticoagulant agents and cancer in the PS-matched cohort.

All data were analyzed using Stata version 14.2 for Windows (StataCorp, College Station, TX, USA).

\section{Results}

Patients, Treatment and Outcome

Tables 1-3 list the baseline characteristics of the enrolled patients with VTE and the characteristics of the subgroups with PE and DVT, respectively. A total of $59.7 \%$ of the subjects were female, with a mean age of $68 \pm 16$ years, and $91.2 \%$ of the population were treated with anticoagulant therapy. Of $6,937(24.5 \%)$ of 28,283 patients with an IVCF, $3,571(51.5 \%)$ and $3,366(48.5 \%)$ had PE (with or without DVT) and DVT, respectively (Figure 1). Patients treated with a filter were younger, and more likely to have worse comorbidity, cancer, and anticoagulant and thrombolytic therapies than those without a filter (Table 1).

Overall, 1,204 patients $(4.3 \%)$ died at a median of 16 days in hospital (Table 1). Of the patients with PE and DVT, 930 $(7.0 \%)$ of 13,303 (Table 2) and $274(1.8 \%)$ of 14,935 died in hospital (Table 3), respectively. Of the patients treated or not with an IVCF, $218(3.1 \%)$ of 6,937 and $987(4.6 \%)$ of $21,301(\mathrm{P}<0.001)$, respectively, died in hospital (Table 1). Fewer patients with PE treated with, than without IVCF died in hospital $(141,3.9 \%$ of 6,937 vs. $789,8.1 \%$ of 9732 , $\mathrm{P}<0.001$; Table 2). Of the patients with DVT treated with and without IVCF, $76(2.3 \%)$ of 3,366 and $198(1.7 \%)$ of $11,569(\mathrm{P}=0.038)$ died in hospital (Table 3).

\section{IVCF and In-Hospital Mortality}

The characteristics of the groups with and without IVCF were closely balanced after PS matching. The in-hospital mortality of matched patients with VTE and PE was lower with, than without IVCF (Tables 1,2). In-hospital mortality 


\begin{tabular}{|c|c|c|c|c|c|c|c|}
\hline \multirow[b]{2}{*}{ Characteristics } & \multirow{2}{*}{$\begin{array}{c}\text { All } \\
\text { participants } \\
(n=13,303)\end{array}$} & \multicolumn{2}{|c|}{ Unmatched patients } & \multirow[b]{2}{*}{ P-value } & \multicolumn{2}{|c|}{ PS-matched patients } & \multirow[b]{2}{*}{ P-value } \\
\hline & & $\begin{array}{l}\text { Without } \\
\text { IVCF } \\
(n=9,732)\end{array}$ & $\begin{array}{c}\text { With } \\
\text { IVCF } \\
(n=3,571)\end{array}$ & & $\begin{array}{l}\text { Without } \\
\text { IVCF } \\
(n=3,400)\end{array}$ & $\begin{array}{c}\text { With } \\
\text { IVCF } \\
(n=3,400)\end{array}$ & \\
\hline Age (years) & $67.9 \pm 15.4$ & $68.4 \pm 15.5$ & $66.3 \pm 15.0$ & $<0.001$ & $67.2 \pm 14.8$ & $67.0 \pm 15.0$ & 0.56 \\
\hline Female & $7,817(58.8)$ & $5,946(61.1)$ & $1,871(52.4)$ & $<0.001$ & $1,832(53.9)$ & $1,857(54.6)$ & 0.54 \\
\hline \multicolumn{8}{|l|}{ Comorbidities at admission } \\
\hline \multicolumn{8}{|l|}{$\mathrm{CCl}$} \\
\hline 0 & $5,125(38.5)$ & $3,747(38.5)$ & $1,378(38.6)$ & 0.11 & $1,347(39.6)$ & $1,308(38.5)$ & 0.76 \\
\hline 1 & 3,925 (29.5) & $2,870(29.5)$ & $1,055(29.5)$ & & $971(28.6)$ & $1,001(29.4)$ & \\
\hline 2 & $2,482(18.7)$ & $1,809(18.6)$ & $673(18.8)$ & & $639(18.8)$ & $638(18.8)$ & \\
\hline$\geq 3$ & $1,771(13.3)$ & $1,306(13.4)$ & $465(13.1)$ & & $443(13.0)$ & $453(13.3)$ & \\
\hline DVT as comorbidity & $5,500(41.3)$ & $3,282(33.7)$ & $2,218(62.1)$ & $<0.001$ & $2,050(60.3)$ & $2,048(60.2)$ & 0.96 \\
\hline \multicolumn{8}{|l|}{ Status on admission } \\
\hline Emergency & $12,099(91.0)$ & $8,763(90.1)$ & $3,336(93.4)$ & $<0.001$ & $3,165(93.1)$ & $3,166(93.1)$ & 0.96 \\
\hline Comatose & $253(1.9)$ & $207(2.1)$ & $46(1.3)$ & 0.002 & $45(1.3)$ & $46(1.4)$ & 0.92 \\
\hline On ventilator & $822(6.2)$ & $627(6.4)$ & $195(5.5)$ & 0.037 & $162(4.8)$ & $187(5.5)$ & 0.17 \\
\hline Catecholamines & $1,042(7.8)$ & $742(7.6)$ & $300(8.4)$ & 0.14 & $259(7.6)$ & $202(8.2)$ & 0.35 \\
\hline Mechanical support & $386(2.9)$ & $306(3.1)$ & $80(2.2)$ & 0.006 & $72(2.1)$ & $80(2.4)$ & 0.51 \\
\hline Blood transfusion required & $642(4.8)$ & $452(4.6)$ & $190(5.3)$ & 0.11 & $152(4.5)$ & $178(5.2)$ & 0.14 \\
\hline Pregnancy & $54(0.4)$ & $37(0.4)$ & $17(0.5)$ & 0.011 & $17(0.5)$ & $13(0.4)$ & 0.55 \\
\hline Cancer & 2,419 (18.2) & $1,690(17.4)$ & $729(20.4)$ & $<0.001$ & $683(20.1)$ & $702(20.6)$ & 0.57 \\
\hline \multicolumn{8}{|l|}{ Anti-thrombotic therapy } \\
\hline Anticoagulants & $12,502(94.2)$ & $8,593(92.3)$ & $3,549(99.4)$ & $<0.001$ & $3,376(99.3)$ & $3,378(99.4)$ & 0.77 \\
\hline Thrombolysis & $1,715(12.9)$ & $940(9.7)$ & 775 (21.9) & $<0.001$ & $629(18.5)$ & $609(17.9)$ & 0.53 \\
\hline \multicolumn{8}{|l|}{ Outcome } \\
\hline Total in-hospital death & $930(7.0)$ & $789(8.1)$ & $141(3.9)$ & $<0.001$ & $205(6.0)$ & $138(4.1)$ & $<0.001$ \\
\hline 7 days & $361(2.7)$ & $332(3.4)$ & $29(0.8)$ & $<0.001$ & $73(2.1)$ & $28(0.8)$ & $<0.001$ \\
\hline 30 days & $743(5.6)$ & 657 (6.8) & $86(2.4)$ & $<0.001$ & $171(5.0)$ & $85(2.5)$ & $<0.001$ \\
\hline
\end{tabular}

Data given as mean \pm SD or $n(\%)$. Abbreviations as in Table 1 .

did not significantly differ between matched patients with DVT treated with and without IVCF (Table 3).

Table 4 lists the results of the mixed-effects logistic regression analyses of PS-matched cohorts with VTE, PE, and DVT. The in-hospital mortality for any type of VTE was significantly lower with, than without IVCF (OR, 0.65; 95\% CI: $0.54-0.79, \mathrm{P}<0.001)$. This association was maintained in the models with 7- and 30-day mortality, instead of total mortality rate, as outcomes, with a lower OR for earlier in-hospital death (OR, 0.31; 95\% CI: $0.20-0.48$ and OR, 0.49; 95\% CI: $0.39-0.61 ; \mathrm{P}<0.001$ for both; Table 4). The total, 7- and 30-day in-hospital mortality rates were similarly reduced in patients with PE, whereas IVCF were not associated with the in-hospital mortality rate in patients with DVT.

To identify which patient factors might be involved in the benefit of IVCF, we analyzed a PS-matched subgroup (Figure 2), and found that age and sex were consistently selected. An IVCF did not significantly affect hospital mortality rate in patients with cancer (Figure 2).

\section{Discussion}

The present study associated IVCF with better survival in patients with VTE, and on PS-matching analyses IVCF was an independent predictor of in-hospital mortality.

The current guidelines for VTE including those of the $\mathrm{ESC}^{15}$ and ACCP, ${ }^{3}$ recommend deploying an IVCF only in patients who are contraindicated for anticoagulation or complicated with active bleeding. These guidelines were based on prospective studies that did not identify a benefit of IVCF, including retrievable types. ${ }^{6,7}$ In Japan, however, patients with VTE and at risk for possible life-threatening PE have been treated with IVCF in addition to anticoagulation. ${ }^{5}$ For instance, a patient with massive PE with residual iliocaval or large free-floating proximal DVT has been treated with an IVCF. ${ }^{16}$ Therefore, the rate at which IVCF are deployed in Japanese patients is $30-40 \%$, which is much higher than in the USA and Europe. .,8,16 $^{-}$

Although many observational studies in USA and Europe have not identified a preventive effect on in-hospital mortality, ${ }^{4,17}$ in the present study IVCF was shown to confer a benefit on survival in patients with VTE treated at cardiovascular teaching hospitals in Japan. These results are similar to those of previous Japanese studies. ${ }^{16,18}$ Some types of bias including selection bias might explain the sharp contrast in IVCF benefit between Japan and elsewhere. Physicians might be more careful about monitoring patients with, than without IVCF. Also, the prescription rate was higher in patients with an IVCF. Another Japanese study found similar tendencies. ${ }^{16}$ Another reason for the international difference in the benefits of IVCF might be the type of anticoagulants used to treat acute VTE. Low-molecularweight heparin (LMWH) is not approved in Japan for VTE treatment. Unfractionated heparin (UFH) is available as a parenteral anticoagulant, but it requires an activated par- 
Table 3. DVT Patient Baseline Characteristics

\begin{tabular}{|c|c|c|c|c|c|c|c|}
\hline \multirow[b]{2}{*}{ Characteristics } & \multirow[b]{2}{*}{$\begin{array}{c}\text { All } \\
\text { participants } \\
(n=14,935)\end{array}$} & \multicolumn{2}{|c|}{ Unmatched patients } & \multirow[b]{2}{*}{ P-value } & \multicolumn{2}{|c|}{ PS-matched patients } & \multirow[b]{2}{*}{ P-value } \\
\hline & & $\begin{array}{c}\text { Without } \\
\text { IVCF } \\
(n=11,569)\end{array}$ & $\begin{array}{c}\text { With } \\
\text { IVCF } \\
(n=3,366)\end{array}$ & & $\begin{array}{c}\text { Without } \\
\text { IVCF } \\
(n=3,307)\end{array}$ & $\begin{array}{c}\text { With } \\
\text { IVCF } \\
(n=3,307)\end{array}$ & \\
\hline Age (years) & $68.4 \pm 16.6$ & $68.5 \pm 16.7$ & $68.2 \pm 16.0$ & 0.36 & $68.3 \pm 16.0$ & $68.1 \pm 16.1$ & 0.63 \\
\hline Female & $9,032(60.5)$ & $7,064(61.1)$ & $1,968(58.5)$ & 0.007 & $1,953(59.1)$ & $1,945(58.8)$ & 0.84 \\
\hline \multicolumn{8}{|l|}{ Comorbidities at admission } \\
\hline \multicolumn{8}{|l|}{$\mathrm{CCl}$} \\
\hline 0 & $6,425(43.0)$ & $5,027(43.5)$ & $1,398(41.5)$ & 0.003 & $1,384(41.9)$ & $1,374(41.5)$ & 0.96 \\
\hline 1 & $3,621(24.2)$ & $2,831(24.5)$ & $790(23.5)$ & & $778(23.5)$ & $779(23.6)$ & \\
\hline 2 & $2,754(18.4)$ & $2,108(18.2)$ & $646(19.2)$ & & $609(18.4)$ & $632(19.1)$ & \\
\hline$\geq 3$ & $2,135(14.4)$ & $1,601(13.8)$ & $532(15.8)$ & & $536(16.2)$ & $522(15.8)$ & \\
\hline PE as comorbidity & $2,088(14.0)$ & $1,212(10.5)$ & $876(26.0)$ & $<0.001$ & $842(25.5)$ & $820(24.8)$ & 0.53 \\
\hline \multicolumn{8}{|l|}{ Status on admission } \\
\hline Emergency & $11,834(79.3)$ & $9,007(77.9)$ & $2,827(84.0)$ & $<0.001$ & $2,761(83.5)$ & $2,772(83.8)$ & 0.71 \\
\hline Comatose & $12(0.1)$ & $10(0.1)$ & $2(0.1)$ & 0.63 & $0(0.0)$ & $2(0.1)$ & 0.16 \\
\hline On ventilator & $49(0.3)$ & $30(0.3)$ & $19(0.6)$ & 0.006 & $11(0.3)$ & $14(0.5)$ & 0.43 \\
\hline Catecholamines & $66(0.4)$ & $39(0.3)$ & $19(0.6)$ & $<0.001$ & $24(0.7)$ & $24(0.7)$ & 1 \\
\hline Mechanical support & $5(0.03)$ & $2(0.02)$ & $3(0.1)$ & 0.045 & $2(0.1)$ & $1(0.05)$ & 0.56 \\
\hline Blood transfusion required & $201(1.3)$ & $116(1.0)$ & $85(2.6)$ & $<0.001$ & $59(1.8)$ & $73(2.2)$ & 0.22 \\
\hline Pregnancy & $471(3.2)$ & $388(3.4)$ & $83(2.5)$ & 0.2 & $80(2.4)$ & $83(2.5)$ & 0.74 \\
\hline Presence of cancer & $2,899(19.4)$ & $2,137(18.5)$ & $762(22.6)$ & $<0.001$ & $746(22.6)$ & $744(22.5)$ & 0.95 \\
\hline \multicolumn{8}{|l|}{ Anti-thrombotic therapy } \\
\hline Anticoagulants & $13,164(88.5)$ & $9,868(85.7)$ & $3,296(97.9)$ & $<0.001$ & $3,274(97.9)$ & $3,273(97.9)$ & 0.93 \\
\hline Thrombolysis & $945(6.3)$ & $601(5.2)$ & $344(10.2)$ & $<0.001$ & $286(8.6)$ & $302(9.1)$ & 0.49 \\
\hline \multicolumn{8}{|l|}{ Outcome } \\
\hline Total in-hospital death & $274(1.8)$ & $198(1.7)$ & $76(2.3)$ & 0.038 & $58(1.8)$ & $73(2.2)$ & 0.19 \\
\hline 7 days & $23(0.2)$ & $22(0.2)$ & $1(0.03)$ & 0.037 & $4(0.1)$ & $1(0.03)$ & 0.18 \\
\hline 30 days & $154(1.0)$ & $119(1.0)$ & $35(1.0)$ & 0.95 & $27(0.8)$ & $34(1.0)$ & 0.37 \\
\hline
\end{tabular}

Data given as mean $\pm \mathrm{SD}$ or $\mathrm{n}(\%)$. Abbreviations as in Table 1 .

\begin{tabular}{|c|c|c|c|c|}
\hline Outcome & Without IVCF & With IVCF & OR (95\% Cl) & P-value \\
\hline \multicolumn{5}{|l|}{ All VTE } \\
\hline Total death & $307 / 6,911(4.4)$ & $211 / 6,911$ (3.1) & $0.65(0.54-0.79)$ & $<0.001$ \\
\hline 7 days & $89 / 6,911$ (1.3) & $30 / 6,911(0.4)$ & $0.31(0.20-0.48)$ & $<0.001$ \\
\hline 30 days & $237 / 6,911$ (3.4) & $120 / 6,911(1.7)$ & $0.49(0.39-0.61)$ & $<0.001$ \\
\hline \multicolumn{5}{|l|}{ PE } \\
\hline Total death & $205 / 3,400(6.0)$ & $138 / 3,400(4.1)$ & $0.66(0.53-0.82)$ & $<0.001$ \\
\hline 7 days & $73 / 3,400(2.1)$ & $28 / 3,400(0.8)$ & $0.35(0.22-0.56)$ & $<0.001$ \\
\hline 30 days & $171 / 3,400(5.0)$ & $85 / 3,400(2.5)$ & $0.48(0.37-0.63)$ & $<0.001$ \\
\hline \multicolumn{5}{|l|}{ DVT } \\
\hline Total death & $58 / 3,307(1.8)$ & $73 / 3,307$ (2.2) & $1.26(0.89-1.79)$ & 0.188 \\
\hline 7 days & $4 / 3,307(0.1)$ & $1 / 3,307(0.03)$ & $0.25(0.03-2.24)$ & 0.215 \\
\hline 30 days & $27 / 3,307(0.8)$ & $34 / 3,307(1.0)$ & $1.25(0.75-2.10)$ & 0.381 \\
\hline
\end{tabular}

Data given as $\mathrm{n}(\%)$. Abbreviations as in Table 1.

tial thromboplastin time-based dose adjustment and it is less effective than LMWH. ${ }^{2}$ In addition to differences in available anticoagulants, potential problems with UFH dose adjustment might affect patient outcome, given that onethird of patients with VTE have been under-dosed with UFH. ${ }^{5}$ Insufficient UFH doses are associated with acutephase VTE recurrence; ${ }^{19}$ an obsolete acute-phase regimen could worsen outcomes for patients treated only with anticoagulants. Given that IVCF deployment techniques and devices do not significantly differ from those elsewhere, anticoagulant strategies to treat acute phase VTE distinctly differ between Japan and other countries. The acute-phase use of DOAC such as apixaban and rivaroxaban, ${ }^{\mathbf{2 0 , 2 1}}$ which are as effective as LMWH for treating VTE, was approved in Japan during 2014. Further study is required to clarify whether the outcomes of VTE treated with anticoagulation in the absence of IVCF can be improved in the DOAC era.

The present study found an association between IVCF 


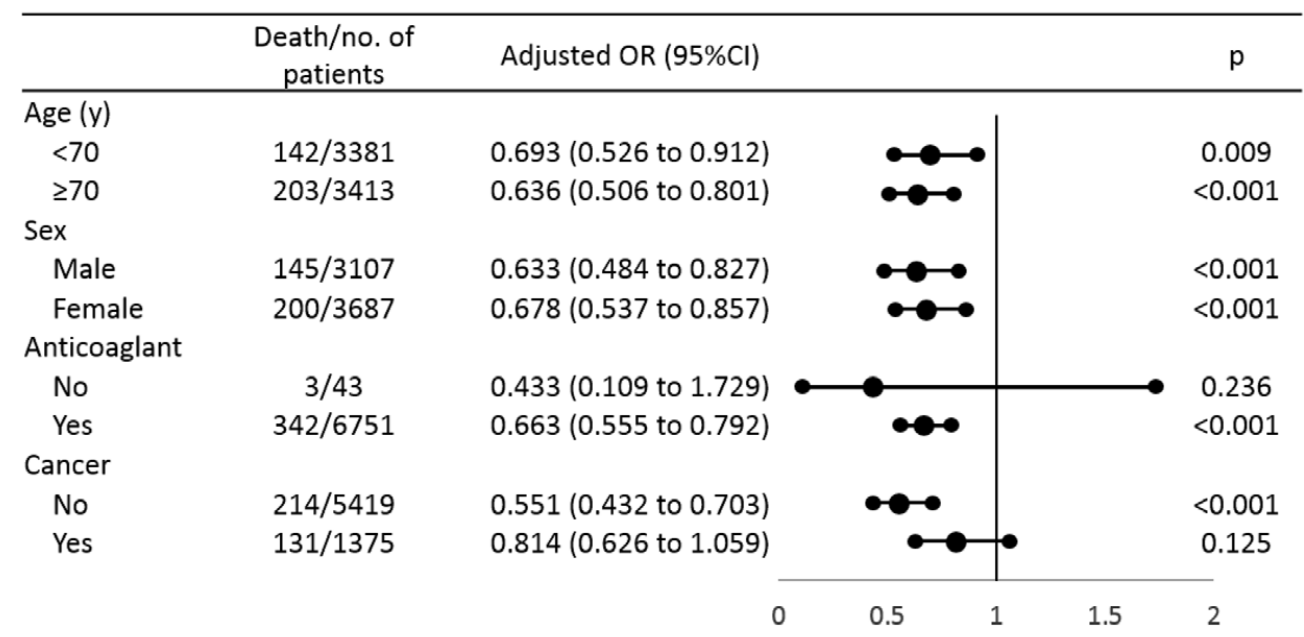

Figure 2. Inferior vena cava (IVC) filter and in-hospital mortality in venous thromboembolism propensity score-matched cohort $(n=13,822)$. Dots and lines, OR and $95 \% \mathrm{Cl}$, respectively.

and in-hospital mortality in patients with PE, but not DVT. Patients with DVT might not benefit from an IVCF, probably due to the lower rate of in-hospital death in the cohort with DVT that received anticoagulants.

On subgroup analysis of patient background, IVCF benefit in-hospital mortality except for patients with cancer. Cancer-associated VTE confers an increase in mortality rate, but the risk of developing major bleeds during anticoagulation therapy is also increased. ${ }^{4}$ Therefore, IVCF deployment is a common therapeutic modality for patients with cancer even though its potential benefits are controversial. ${ }^{22}$ Given that higher in-hospital mortality was noted in the present cohort with VTE and with, than without cancer $(9.5 \%$ vs. $3.9 \%)$, any benefit of IVCF would be blunted in patients with cancer. ${ }^{9}$

\section{Study Limitations}

This study had several limitations. The accuracy of the diagnosis and procedures are unclear, because these are less validated in the DPC database compared with planned prospective studies. In addition, the database did not contain information on echocardiography parameters or laboratory data such as right ventricular function or cardiac troponin levels, which are commonly used as severity markers for PE and are associated with prognosis. ${ }^{15}$ Instead, we used mechanical ventilation and catecholamine medication as markers of PE severity. A residual imbalance in severity in patients with PE and with and without IVCF, however, might have affected the results even in the PS analyses. The database did not have information on the clinical indications for IVCF insertion or type of IVCF (i.e., permanent type or retrievable type). The prognostic difference of these IVCF types is unknown so far. ${ }^{4}$ The permanent type may lead to DVT recurrence, and the retrievable type may be related with device retrieval-related complications. ${ }^{4}$ Further precise analysis focused on IVCF type is required. With regard to statistical limitations, type I error might have been inflated due to multiple tests.

We focused on the short-term benefit of IVCF. Given that a known IVCF-related disadvantage is DVT recurrence in 2-8 years of follow-up, ${ }^{\mathbf{6}, 7,23}$ we were unable to provide information on the long-term IVCF effects. According to guidelines, retrievable IVCF and the removal of IVCF in a few days to weeks should be recommended, because the present findings support only in-hospital outcome as a benefit of IVCF. We could not identify specific clinical indications for IVCF deployment. A contraindication to anticoagulation was not an issue because almost all patients with an IVCF were also treated with anticoagulants. According to observational studies in Japan, significant bleeds or surgery during hospitalization would be major indications for an IVCF.5,16 Generalization of the present findings to other countries is limited, because all data were extracted from a purely Japanese database. Clinical practice for VTE might vary between countries, especially in terms of the anticoagulant and the rate of IVCF. A causal relationship between IVCF with mortality was unclear due to the observational nature of this study. The strength of this study is the large sample size based on real-world data extracted from JROAD-DPC.

\section{Conclusions}

Being treated with an IVCF was independently associated with lower in-hospital mortality rates in patients with VTE in Japan, in sharp contrast to those in other nations. Prospective studies are necessary to confirm the benefit(s) of IVCF, and an additional cohort study is required to show the role of IVCF in the era of DOAC, given that acute anticoagulant regimens have become similar around the world.

\section{Acknowledgments}

This work was supported by Grant-in-Aid for Scientific Research from Japan Society for the Promotion of Science, the Ministry of Education, Culture, Support, Science, and Technology (to M.K.), and the Gunma University Initiative for Advanced Research (to M.K.).

\section{Disclosures}

The authors declare no conflicts of interest. 


\section{References}

1. Goldhaber SZ, Bounameaux H. Pulmonary embolism and deep vein thrombosis. Lancet 2012; 379: 1835-1846.

2. Wells PS, Forgie MA, Rodger MA. Treatment of venous thromboembolism. JAMA 2014; 311: 717-728.

3. Kearon C, Akl EA, Ornelas J, Blaivas A, Jimenez D, Bounameaux $\mathrm{H}$, et al. Antithrombotic therapy for VTE disease: CHEST guideline and expert panel report. Chest 2016; 149: 315-352.

4. Duffett L, Carrier M. Inferior vena cava filters. J Thromb Haemost 2017; 15: 3-12.

5. Nakamura M, Miyata T, Ozeki Y, Takayama M, Komori K, Yamada N, et al. Current venous thromboembolism management and outcomes in Japan. Circ J 2014; 78: 708-717.

6. Decousus H, Leizorovicz A, Parent F, Page Y, Tardy B, Girard $\mathrm{P}$, et al. A clinical trial of vena caval filters in the prevention of pulmonary embolism in patients with proximal deep-vein thrombosis: Prevention du Risque d'Embolie Pulmonaire par Interruption Cave Study Group. N Engl J Med 1998; 338: 409-415.

7. Mismetti P, Laporte S, Pellerin O, Ennezat PV, Couturaud F, Elias A, et al. Effect of a retrievable inferior vena cava filter plus anticoagulation vs anticoagulation alone on risk of recurrent pulmonary embolism: A randomized clinical trial. JAMA 2015; 313: $1627-1635$.

8. Muriel A, Jimenez D, Aujesky D, Bertoletti L, Decousus H, Laporte S, et al. Survival effects of inferior vena cava filter in patients with acute symptomatic venous thromboembolism and a significant bleeding risk. J Am Coll Cardiol 2014; 63: 1675-1683.

9. Brunson A, Ho G, White R, Wun T. Inferior vena cava filters in patients with cancer and venous thromboembolism (VTE) does not improve clinical outcomes: A population-based study. Thromb Res 2017; 153: 57-64.

10. Mellado M, Pijoan JI, Jimenez D, Muriel A, Aujesky D, Bertoletti $\mathrm{L}$, et al. Outcomes associated with inferior vena cava filters among patients with thromboembolic recurrence during anticoagulant therapy. JACC Cardiovasc Interv 2016; 9: 2440-2448.

11. Harris SA, Velineni R, Davies AH. Inferior vena cava filters in pregnancy: A systematic review. J Vasc Interv Radiol 2016; 27: 354-360.e8.

12. Yasuda S, Nakao K, Nishimura K, Miyamoto Y, Sumita Y, Shishido T, et al. The current status of cardiovascular medicine in Japan: Analysis of a large number of health records from a nationwide claim-based database, JROAD-DPC. Circ J 2016; 80: $2327-2335$.
13. D'Agostino RB Jr. Propensity score methods for bias reduction in the comparison of a treatment to a non-randomized control group. Stat Med 1998; 17: 2265-2281.

14. Quan H, Li B, Couris CM, Fushimi K, Graham P, Hider P, et al. Updating and validating the Charlson comorbidity index and score for risk adjustment in hospital discharge abstracts using data from 6 countries. Am J Epidemiol 2011; 173: 676-682.

15. Konstantinides SV, Torbicki A, Agnelli G, Danchin N, Fitzmaurice $\mathrm{D}$, Galie N, et al. 2014 ESC guidelines on the diagnosis and management of acute pulmonary embolism. Eur Heart J 2014; 35: 3033-3069, 3069a-3069k.

16. Yamashita $Y$, Unoki T, Takagi D, Hamatani $Y$, Ishii M, Iguchi $\mathrm{M}$, et al. Indications, applications, and outcomes of inferior vena cava filters for venous thromboembolism in Japanese patients. Heart Vessels 2016; 31: 1084-1090.

17. White RH, Brunson A, Romano PS, Li Z, Wun T. Outcomes after vena cava filter use in noncancer patients with acute venous thromboembolism: A population-based study. Circulation 2016; 133: $2018-2029$.

18. Isogai $T$, Yasunaga $H$, Matsui $H$, Tanaka $H$, Horiguchi $H$, Fushimi K. Effectiveness of inferior vena cava filters on mortality as an adjuvant to antithrombotic therapy. Am J Med 2015; 128: 312.e23-e31.

19. Hull RD, Raskob GE, Hirsh J, Jay RM, Leclerc JR, Geerts WH, et al. Continuous intravenous heparin compared with intermittent subcutaneous heparin in the initial treatment of proximalvein thrombosis. $N$ Engl J Med 1986; 315: 1109-1114.

20. Agnelli G, Buller HR, Cohen A, Curto M, Gallus AS, Johnson $\mathrm{M}$, et al. Oral apixaban for the treatment of acute venous thromboembolism. N Engl J Med 2013; 369: 799-808.

21. Prins MH, Lensing AW, Bauersachs R, van Bellen B, Bounameaux $\mathrm{H}$, Brighton TA, et al. Oral rivaroxaban versus standard therapy for the treatment of symptomatic venous thromboembolism: A pooled analysis of the EINSTEIN-DVT and PE randomized studies. Thromb J 2013; 11: 21.

22. White RH, Geraghty EM, Brunson A, Murin S, Wun T, Spencer $\mathrm{F}$, et al. High variation between hospitals in vena cava filter use for venous thromboembolism. JAMA Intern Med 2013; 173: $506-512$.

23. PREPIC Study Group. Eight-year follow-up of patients with permanent vena cava filters in the prevention of pulmonary embolism: The PREPIC (Prevention du Risque d'Embolie Pulmonaire par Interruption Cave) randomized study. Circulation 2005; 112: 416-422. 